J. Asiat. Soc. Bangladesh, Sci. 46(1): 61-70, June 2020

\title{
STOCK SEPARATION OF TENUALOSA ILISHA IN BANGLADESH WATERS USING PARASITES AS BIOLOGICAL TAG
}

\author{
MD. AMINUL ISLAM BHUIYAN* AND ZANNATUN NAHAR JHINU \\ Department of Zoology, University of Dhaka, Dhaka-1000, Bangladesh
}

\begin{abstract}
Fourteen species under eleven genus of endohelminths were identified from alimentary canal and associated organs of host, only two of them had satisfied the criteria of being as biological tag. These are one species of cestode parasite named Ilisha parthenogenetica and two acanthocephalan parasite species named Acanthocentis indica and Acanthocentis hilsai, which are in together termed as Acanthosentis spp. The presence of these parasites in all the habitats indicates host's anadromous nature as well as higher prevalence of these tag parasites at respective sites and the trend of prevalence of infection in size class of host fish reinforced the belief that T. ilisha population in Bangladesh are largely anadromous in nature that cannot currently be divided into a group of discrete stocks and as a whole, a single stock of T. ilisha migrates from the sea to the rivers through the estuaries and vice versa.
\end{abstract}

Key words: Tenualosa ilisha, Stock separation, Parasite, Biological tag

\section{Introduction}

The 'Hilsa shad', Tenualosa ilisha belonging to the order Clupeiformes occurs in foreshore areas, estuaries, brackish-water lakes and freshwater rivers of south and south East Asia especially in Bangladesh (Pillay and Rosa 1963). Hilsa shad is the largest single fishable species in Bangladesh, present in almost all the major river systems, estuaries and marine environments (Bay of Bengal).

The Hilsa shad is largely an anadromous species, but two other ecotypes - a fluvial potamodromous type and a marine type - have also been recognized (Raja 1985). The anadromous stocks, whose normal habitat is the lower region of the estuaries and the foreshore areas, ascend the rivers during the breeding season and return to the original habitat after spawning (Raja 1985). The potamodromous stocks (river stocks) appear to remain in the middle reaches of the rivers throughout the year and breed there in. Marine stocks live all their life in the foreshore of the sea and not migrating to the river system (Amin et al. 2004). These stocks may differ in various aspects of their life history such as having different spawning grounds or feeding areas.

*Corresponding author: aminul_zool@du.ac.bd 
The commercial value of this species has led to the use of parasites as biological marker for precise identification and definition of fish stocks as well as knowledge of the parasitic fauna and the spatial distribution of both parasite and fish population (Mosquera et al. 2000). Many different groups of parasites make suitable biological tags for stock separation, mainly because it is not usually necessary to select for parasites with long life spans in the subject host as well as being a natural process which avoid the stress associated with capture, handling and possible abnormal behavior of mechanically tagged species (Mackenzie 1987).

The purpose of the present study was to determine if parasites could be used to distinguish between different stocks of Tenualosa ilisha occurring in Bangladesh waters and, if so, to determine the stock composition and structure to identify intraspecific groups which are distinguished by different patterns of behaviors at certain stages of their life history within 'hilsa' population in Bangladesh waters.

\section{Materials and Methods}

The study was aimed at analyzing the stock composition and discriminating the stock of adolescent Tenualosa ilisha in Bangladesh waters using data on metazoan endoparasites, more specifically gut endohelminths as biological tags. Primary selection of parasites as

biological tags was executed by using established criteria and then inferences were drawn on stock composition and stock discrimination.

Selection criteria of tag parasite to study fish stock composition: The sets of criteria for the study of anadromous fish stock (hilsa) in Bangladesh might be best fitted with the Margolis et al. (1982) selection criteria for salmonids. The criteria are mentioned as follows:

1. The parasite must be present in one stock or group of stocks and absent or rare in others.

2. The parasite infection should occur within a limited area and time before the stock become mixed in the ocean.

3. The parasite should have significantly different levels of infection in the target host in different parts of the study area.

4. The parasite might have long life span, preferably as long as that of its fish host, or at least as long as that period of the host's life over which observation on stock was being made. 
5. The parasite should have no marked effects on survival and behavior of the fish if the parasite is to be used to estimate proportions of stock in a mixed stock sample.

6. The parasite should be easily detected and identified.

Selection of variable: Prevalence is considered to be a most useful parameter as it is less variable and represents the entire data set (both infested and non-infested fish) that is used as an indicatory variable for tagging in this study.

Sample collection: A total of 2667 host fish, Tenualosa ilisha were collected from three different ecological habitats of Bangladesh waters, to be more specific 1565 host fishes from the rivers in Chandpur $\left(23^{\circ} 14.40 \mathrm{~N} 90^{\circ} 40.73 \mathrm{E}\right)$, Aricha $\left(23^{\circ} 46.10 \mathrm{~N} 89^{\circ} 46.83 \mathrm{E}\right)$,


estuaries in Patuakhali $\left(22^{\circ} 21.42 \mathrm{~N} 90^{\circ} 21.10 \mathrm{E}\right)$, Barguna $\left(22^{\circ} 09.45 \mathrm{~N} 90^{\circ} 07.61 \mathrm{E}\right)$, Bhola $\left(22^{\circ} 43.10 \mathrm{~N} 90^{\circ} 40.53 \mathrm{E}\right)$, Barishal $\left(22^{\circ} 42.23 \mathrm{~N} 90^{\circ} 22.49 \mathrm{E}\right)$ and Sandwip $\left(22^{\circ} 30.56 \mathrm{~N} \mathrm{91}{ }^{\circ} 42.78 \mathrm{E}\right) ; 493$ host fishes from the sea in Cox's Bazar $\left(21^{\circ} 25.09 \mathrm{~N}\right.$ $\left.91^{\circ} 59.97 \mathrm{E}\right)$ and Kuakata $\left(21^{\circ} 48.97 \mathrm{~N} 90^{\circ} 07.32 \mathrm{E}\right)$.

Sample processing: Both morphometric and meristic characteristics of the host fishes were analyzed and the weight, length and sex of each fish were recorded. The viscera and organs (cardiac stomach, pyloric caeca, stomach, intestine and mesenteries) were removed individually through simple dissection and kept in $10 \%$ formalin in polyethylene bags with a label inside. Laboratorial analysis was performed at Parasitology laboratory, Department of Zoology, University of Dhaka, Dhaka, Bangladesh. Extensive search was made for helminth parasites infecting the fish using microscope. Parasites from each organ were sorted, cleaned and counted which was followed by preservation in $70 \%$ alcohol. Berland's methods were used for staining and mounting.

Data analysis: As parasites counts were not normally distributed, nonparametric ANOVA using ranked scores (SAS PROC GLM procedure) was performed to accomplish multivariate analysis among samples of different habitat. Square root transformation of parasite numbers was done to bring frequency distribution close to normal for ANOVA. All statistical tests were done by SAS version-6. Only the data on component parasites were used in calculation.

\section{Results and Discussion}

The biological tag studies are usually based on differences in prevalence of infection between samples of different ecological habitats. A rich and versatile parasitic fauna have 
been found in host fish, Tenualosa ilisha in the study. Overall 14 species under 11 genus of endohelminths have been collected and identified from alimentary canal and associated organs (mesenteries and caeca). These are five trematode species: Aphanurus stossichi, Faustula brevichrus, F. gangetica, F. ilishii, Lecithaster indicus; two cestode species: Ilisha parthenogenetica (plerocercoid) and Otobothrium ilisha (plerocercoid); five nematode species: Goezia bangladeshi (adult and larvae), Camallanus sp. (larvae), Porrocaecum sp. (larvae), Capillaria sp. (larvae) and Hysterothylacium sp. (larvae) and two acanthocephalan species: Acanthosentis indica and Acanthosentis hilsai. Three species of Faustula were counted together and referred as Faustula spp. and two species of Acanthocentis were counted together and referred as Acanthosentis spp.

All of them were present in freshwater, brackish and salt water stock indicating a remarkable spatial stability. Prevalence of different parasites in Tenualosa ilisha from three different habitats such as freshwater, brackish water and marine water bodies are shown in Table 1.

Table 1. Prevalence (\%) of different parasite species in different habitats.

\begin{tabular}{|c|c|c|c|c|c|}
\hline Group & Parasites & $\begin{array}{l}\text { Fresh } \\
\text { water }\end{array}$ & $\begin{array}{l}\text { Brackish } \\
\text { water }\end{array}$ & Marine & $\mathrm{p}$ \\
\hline \multirow[t]{3}{*}{ Trematoda } & Aphanurus stossichi & 77.45 & 94.80 & 91.70 & $>0.05 \mathrm{NS}$ \\
\hline & Faustula spp. & 49.13 & 77.89 & 67.17 & $>0.05 \mathrm{NS}$ \\
\hline & Lecithaster indicus & 17.16 & 58.72 & 29.43 & $<0.05 *$ \\
\hline \multirow[t]{2}{*}{ Cestoda } & Otobothrium ilisha & 1.92 & 0.00 & 1.51 & $>0.05 \mathrm{NS}$ \\
\hline & Ilisha parthenogenetica & 4.02 & 38.23 & 11.32 & $<0.01 * *$ \\
\hline \multirow[t]{5}{*}{ Nematoda } & Goezia bangladeshi & 34.76 & 31.80 & 34.34 & $>0.05 \mathrm{NS}$ \\
\hline & Camallanus sp. & 1.00 & 0.00 & 0.38 & $>0.05 \mathrm{NS}$ \\
\hline & Capillaria sp. & 1.40 & 0.61 & 0.75 & $>0.05 \mathrm{NS}$ \\
\hline & Porroceacum sp. & 1.00 & 0.00 & 0.75 & $>0.05 \mathrm{NS}$ \\
\hline & Hysterothylacium sp. & 10.20 & 2.75 & 1.51 & $>0.05 \mathrm{NS}$ \\
\hline Acanthocephala & Acanthosentis spp. & 8.40 & 3.36 & 4.91 & $<0.01 * *$ \\
\hline
\end{tabular}

NS, not significant; *significant at 5\% level and **significant at $1 \%$ level. Three species of Faustula were counted together and referred as Faustula spp. And two species of Acanthocentis were counted together and referred as Acanthosentis spp.

Of the parasites only 9 had the status of component parasite (prevalence above 10\%) (Bush et al. 1990). These are Aphanurus stossichi, Lecithaster indicus, Faustula brevichrus, F. gangetica, F. ilishii, Ilisha parthenogenetica, Goezia bangladeshi, 
Acanthosentis indica and Acanthosentis hilsai. Prevalence of only three species of them named Lecithaster indicus, Ilisha parthenogenetica and Acanthosentis spp. were distinctly different which were statistically significant. However, short life span $(<1$ year) of $L$. indicus (adult digenean) in the alimentary canal of fish limited their use as biological tags. Therefore Ilisha parthenogenetica and Acanthosentis spp. were appeared to be satisfied with the selection criteria due to their long survival (several years) often for the life of the fish for the use of parasites as tags to study stock composition. It can be compared with the work of Stanley et al. (1992), in which study only 2 parasites were found out of 25 and Boje et al. (1997), in which study 6 parasites were found out of 21 to satisfy the criteria of tag parasite.

A number of researchers (Khan et al. 1980, Gaevkaya and Shapiro 1981, MacKenzie and Mehl 1984, Bamber and Henderson 1985) concluded that for fish which spend their entire lives in either marine or freshwater such parasites are often found throughout the host range and stocks are separated by differences in prevalence or mean intensity of infection. The dominant component of parasite faunas, however, does not necessarily make the best tags. Species which occur less commonly or only as incidental parasites of the host being studied are probably the most convincing. Therefore the role of incidental parasites as tags is also discussed. These parasites can only be acquired by the host in the restricted areas within its range. Outside these enzootic areas the life cycle of the parasite cannot be completed because conditions are unfavorable.

An obvious requirement of tag parasites are significantly different levels of infection in the subject host in different ecological sites of study area. This is based on the premise that each site has its own characteristic parasite community which a migrant host may acquire or lose as it travels. In this study among the component parasites the prevalence of Faustula spp., A. stossichi, L. indicus and Goezia bangladeshi did not vary considerably between sites but that of I. parthenogenetica and Acanthosentis spp. varied. Detection of encysted or free Acanthosentis spp., Goezia bangladeshi and I. parthenogenetica or free adult $L$. indicus in different sites requires little dissection. They are clearly visible to the naked eye or dissection microscope and are identified easily. In their fish intermediate or paratenic host they are present as encysted or free during which no feeding take place; therefore no pathological impact is likely to be observed. Also, they are likely to have long life spans. Prevalence of helminthic infection in each sampling sites were observed (Table 2). 





It is evident (Table 2) that among the component parasites, I. parthenogenetica had higher prevalence in brackish water stock, respectively in Barguna, (54.74\%), Barishal (42.65\%) and Sandwip (37.14\%). On the contrary, Acanthosentis spp. had higher prevalence in freshwater stock, respectively in Sherpur (22.03\%), Paksey (15.90\%), Aricha $(8.36 \%)$ and Chandpur $(4.83 \%)$. Though the prevalence of infection by nematodes was very low, they occurred more or less in almost all the sites.

To exemplify, the prevalence of $I$. parthenogenetica and Acanthosentis spp. was measured in respect of the body length of host fishes that can be resembled with their age or life stages. Host fishes were divided into nine arbitrary groups according to their length which ranges between 17.2 and $58 \mathrm{~cm}$.

The results on distribution of parasites in different size groups indicate that $I$. parthenogenetica had highest prevalence (22.73\%) in the smallest size group of hilsa in freshwater. In brackish water the prevalence of I. parthenogenetica was relatively higher than the freshwater and it showed conformity in Group-2 to Group-5 size classes (33.33 $41.9 \%$ ) that was followed by fluctuations in the larger groups (Group-6 to Group-9) ranging $14-60.61 \%$. The higher prevalence of $I$. parthenogenetica in brackish water sites especially in middle size class indicated that the cestode parasite was recruited in brackish water sites after or before the host fish, 'hilsa shad' migrated to the other sites and the host fish spent there much time for feeding. In marine habitats, prevalence of $I$. parthenogenetica did not show any pattern with regard to the size groups of host fish and no I. parthenogenetica could be found in the smallest and the largest groups (Table 3).

Similarly, Acanthosentis spp. showed the highest prevalence in the smallest size group and infected all groups except largest size group (group-9) in the freshwater habitat while in brackish water and marine samples no fish were found infected in smaller size classes $\left(1^{\text {st }}\right.$ and $2^{\text {nd }}$ groups). In brackish water, Acanthosentis spp. infection was found only in the middle groups (Group-3 to Group-5). In marine sample, Acanthosentis spp. was found in the middle and larger groups ( $4^{\text {th }}$ to $8^{\text {th }}$ groups) (Table 3$)$. The higher prevalence of Acanthosentis spp. in freshwater sites indicated that this parasite was recruited in the freshwater stock before or after migrating to sea or estuary.

Therefore, both the prevalence in different size groups and in different sites supported the assumption that Acanthosentis spp. was recruited in freshwater and I. parthenogenetica was recruited in brackish water habitats in host, Tenualosa ilisha in Bangladesh. The results on distribution of parasites in respect of size specify that the hilsa acquired infection of Acanthosentis spp. in the freshwater stock at a very tender age whereas, infection of Acanthosentis spp. was found in middle aged in brackish water stocks and in 





middle and older age in marine stocks. This trend of Acanthosentis spp. infection supported the postulation that as the T. ilisha fishes become larger they move to the estuarine and marine stock.

Prevalence of Goezia bangladeshi did not vary widely in size classes of freshwater hilsa. It ranged from 29.88 - 50\%. In brackish water prevalence in hilsa of Goezia bangladeshi was almost similar in $2^{\text {nd }}$ to $6^{\text {th }}$ class. Prevalence varied greatly in the larger size classes $\left(7^{\text {th }}-9^{\text {th }}\right.$ groups). In marine hilsa higher prevalence of the parasite was observed in intermediate to larger size class.

Except for Acanthosentis spp. and I. parthenogenetica infection, there was little difference in the rest of the parasite fauna of T. ilisha captured in freshwater, brackish water and salt water. Several salt water parasites (notably all the trematodes and nematodes) were common in fish captured in freshwater and brackish water, illustrating the ability of these parasites to survive in their host during movement into estuarine and freshwater conditions. The scarcity of freshwater parasites in the T. ilisha suggested that although they do enter freshwater, most probably they do not spend extended periods of time feeding there. Additionally, the presence of some larval nematodes (incidental parasites) that have sea mammals (cetaceans) as their definitive hosts and which were found in all the habitats indicated that T. ilisha serves as an intermediate host of those parasites and travel from sea to freshwater via the estuary.

So it can be inferred that, the consistent prevalence of parasites which are not site specific (trematodes) and higher prevalence of Acanthosentis spp. and I. parthenogenetica parasites at respective sites which are site specific reinforced the belief that the hilsa, as a whole, migrates from the sea to the rivers via the estuaries and vice versa. Moreover, the presence of all the parasites in all the habitats and the trend of prevalence of infection in size class of hilsa (Table 3 ) indicated that $T$. ilisha population in Bangladesh are largely anadromous in nature that cannot currently be divided into a group of discrete stocks. Moreover, no other published information is available on stock composition or stock discrimination based on parasitological data, which limits the scope of direct comparison. Even results of earlier works using different method on stock composition based on different techniques (other than biological tags) are inconclusive.

Blaber et al. (2003) supported the inference as they failed to find any evidence of more than one stock of T. ilisha in Bangladesh waters. This study was based on genetic (allozymes), morphometrics and otolith microchemistry and concluded that T. ilisha mix and move through the country in different direction without any pattern. Conversely, Rahman et al. (1997) found that the riverine stocks of hilsa shad are significantly 
different in genetic structure from those found in the marine environment and on the basis of morphometric and meristic characters. Rahman et al. (1998) predicted the possibility of having at least four stocks of hilsa in Bangladesh waters. However, extensive study over longer period on life cycle of the parasites and biology of hilsa will reveal more accurate conclusion on T. ilisha movements and stock composition in Bangladesh.

\section{References}

Amin, S.M.N., M.A. Rahman, G.C. Haldar, M.A. Mazid, D. Milton and S.J.M. Blaber. 2004. Stock assessment and management of Tenualosa ilisha in Bangladesh. Asian Fisheries Science 17: 51-59.

Bamber, R.N. and P.A. Henderson. 1985. Diplostomiasis in sand smelt Atherina presbyter Cuvier from the Fleet, Dorset and its use as a population indicator. Journal of Fish Biology 26: 223-229.

Blaber, S.J.M., D.A. Milton, S.R. Chenery and G. Fry. 2003. New insights into the life history of Tenualosa ilisha and fishery implications. American Fisheries Society Symposium 35: 223-240.

Boje, J., F. Riget and M. Koie. 1997. Helminth parasites as biological tags in population studies of Greenland halibut (Reinharditus hippoglossoides (Walbaum)), in the north-west Atlantic. ICES J. Marine Science 54: 886-895.

Bush, A.O., J.M. Aho and C.R. Kennedy. 1990. Ecological verses phylogenetic determinants of helminth parasite community richness. Evolutionary Ecology 4: 1-20.

Gaevskaya, A.V. and L.S. Shapiro. 1981. The question of the local nature of Baltic herring (Clupea harengus membras L.) in the Vistula lagoon of the Baltic Sea: Stock State and principles of the Rational Fishery in the Atlantic. pp. 11-79.

Khan, R.A., M. Barrett and J. Murphy. 1980. Blood parasites of fish from the Northwestern Atlantic Ocean. Can. J. Zool. 58: 770-781.

Mackenzie, K. and Mehl. 1984. The cestode parasite Grillotia angeli as a biological tag for mackerel in the eastern North Atlantic ICES CM. 52: 7.

Mackenzie, K. 1987. Parasite as indicators of host populations. Int. J. Parasitol. 17: 345-352.

Margolis, L., G.W. Esch, J.C. Holmes, A.M. Kuris and G.A. Schad. 1982. The use of ecological terms in parasitology. (Report of an ad hoc committee of the American Society of Parasitologists.). $J$. Parasitol. 68(1): 131-133.

Mosquera, J.M., G. Gomez and V. Perez. 2000. Using Parasites as Biological Tags of Fish Populations: A Dynamical Model. Bulletin of Mathematical Biology 62: 87-99.

Pillay, S.R. and H. Rosa. 1963. Synopsis of biological data on Hilsa, Hilsa ilisha (Hamilton 1822.). FAO Fisheries Synopsis. 25: 61.

Rahman, M.A., M.A. Mazid, M.S. Islam, N.J. Rahman and G. Moula. 1997. Experimental pond culture of hilsa, Tenualosa ilisha (Hamilton) at chandpur, Riverine station. Bangladesh J. Fish 20: 131-133.

Rahman, M.J., M.G. Mustafa and M.A. Rahman. 1998. Population dynamics and recruitment pattern of hilsa, Tenualosa ilisha. In: Mazid, M.A., Blaber, S.J.M. (Eds.), Hilsa Fisheries Research in Bangladesh. Proceedings of the BFRI/ACIAR/CSIRO Workshop, 3-4 March. Dhaka, Bangladesh, pp. 28-36. Hilsa Fisheries Research in Bangladesh 86: 20-27.

Raja, B.T.A. 1985. A review of the biology and fisheries of Hilsa ilisha in the upper Bay of Bengal. Proceedings of the Marine Fisheries Resourse Management, Bay of Bengal, Colombo, Sri Lanka. FAO/UNDP BOBP/WP. 37: 66.

Stanley, R.D., D.L. Lee and D.J. Whitaker. 1992. Parasites of yellowtail rockfish, Sebastes flavidus from the pacific coast of North America as potential biological tags for stock identification. Can. J. Zool. 70: 1086-1096.

(Revised copy received on 19.03.2020) 